Obesity, hypertension and glucose tolerance disorders have become a growing concern in recent years. It is estimated that over 220 million people suffer from diabetes. It is a condition conducive to cardiovascular diseases, nephropathy, retinopathy and neuropathy but also to the development of many types of cancer. Insulin resistance and hyperinsulinemia lead to increased concentration of insulin-like growth factors, activation of IGF-R receptors, activation of PI3K and Ras-Raf pathways and result in increased cell division. The greatest risk is associated with developing stomach, pancreatic, colorectal, esophageal and lung cancer as well as breast and cervical cancer. Numerous cohort studies have confirmed that diabetic patients treated with metformin show a lower cancer morbidity and mortality rate. The dominant mechanism of action is activation of the AMP-activated protein kinase (AMPK) pathway and inhibition of mTOR protein, the key protein to regulate cell growth, apoptosis, proliferation and protein synthesis. Many clinical trials are currently under way to investigate the effectiveness of metformin in the prevention and treatment of neoplasms.

Key words: metformin, oncological treatment, diabetes, AMPK, mTOR.

\section{The influence of metformin in the etiology of selected cancers}

\author{
Monika Pawałowska ${ }^{1}$, Anna Markowska²
}

1Department of Oncology, Poznan University of Medical Sciences, Poznan, Poland 2Department of Perinatology and Gynecology, Poland University of Medical Sciences, Poznan, Poland

\section{Introduction}

According to data gathered by World Health Organization (WHO) from 2008, approximately 1.5 billion people aged 20 and older were overweight [BMI (body mass index) $25-29.9 \mathrm{~kg} / \mathrm{m}^{2}$; m more than 200 million men and almost 300 million women were classified as obese (BMI > $\left.30 \mathrm{~kg} / \mathrm{m}^{2}\right)$. Between 1980 and 2008 the number of obese people doubled. It is widely known that factors such as obesity, lack of physical activity, and high-carbohydrate diet are conducive to glucose tolerance disorder. According to WHO figures from 2011, over 220 million people are suffering from diabetes in the world. The International Diabetes Federation (IDF) estimates that by 2025 the number of people with impaired glucose tolerance will increase to 472 million (9\% of the adult population), of whom around 40-50\% will develop type 2 diabetes. Recent studies show that diabetes is conducive not only to cardiovascular diseases, nephropathy, retinopathy and neuropathy, but also to the development of many types of cancers [1-4]. Recent data have shown that metformin, a drug commonly used in diabetic patients, can significantly decrease the incident rate and death risk associated with malignant cancers. In this paper we would like to present the mechanism of metformin's anticancer action and its role in selected malignancies.

\section{Diabetes and cancer}

Despite a tremendous body of research conducted in this field, there are still many aspects of the pathomechanism associating diabetes with cancer development that remain unclear.

Intense protein synthesis and rapid cell division within cancerous tissue demand high energy consumption. Therefore the proliferating cells need to ensure themselves a constant delivery of the basic energy source that is glucose. In the case of hypoglycemia cancer cells rely on glycosylation to produce ATP (the Warburg effect) [5]. Some authors have shown that hyperglycemia is connected with increased risk of cancer. Park et al. [4] compared populations of patients with a fasting serum glucose level under $109 \mathrm{mg} / \mathrm{dl}$ and above $126 \mathrm{mg} / \mathrm{dl}$ and showed that the cancer-related mortality rate was $38 \%$ higher in the latter group. The highest mortality in that group was associated with gastric cancer (HR: 1.52; 95\% Cl: 1.25-1.84) and lung cancer (HR: $1.48 ; 95 \% \mathrm{Cl}: 1.18-1.87$ ). Jee et al. came to similar conclusions [6]. In this Korean study a significant increase in mortality rate was found among people with the fasting serum glucose level over $140 \mathrm{mg} / \mathrm{dl}$ when compared with a group with the level under $90 \mathrm{mg} / \mathrm{dl}$ (HR: 1.29; 95\% Cl: 1.22-1.37 among men and HR: 1.23 ; $95 \% \mathrm{Cl}: 1.09-1.39$ among women). In the male population the highest death rate was associated with esophageal (HR: $1.44 ; 95 \% \mathrm{Cl}$ : 1.08-1.93), liver (HR: 1.57; 95\% Cl: 1.40-1.76), pancreatic (HR: 1.91; 95\% Cl: $1.52-$ 2.41) and colorectal (HR: 1.31; 95\% Cl: 1.03-1.67) cancer. The highest death 
rate among women suffering from diabetes with fasting blood glucose level in the morning over $140 \mathrm{mg} / \mathrm{dl}$ was associated with liver (HR: 1.33; Cl: 1.01-1.81), lung (HR: 1.50; Cl: 0.94-1.78), breast (HR: 1.24; Cl: 0.65-1.92) and cervical (HR: 1.81; Cl: 1.03-3.15) cancer; however, no such association was found for gastric and colorectal cancer.

On the other hand, in most cases normoglycemia allows for a concentration of glucose appropriate to meet the needs of cancerous cells [7]. A meta-analysis by Johnson and Bowker [8] assessed the benefits of an intensified glycemic control in patients with type 2 diabetes in the context of development of neoplasms. In the conclusion of the large randomized study which included populations of many thousands of patients, the authors did not find any decrease in the risk of cancer mortality rates among patients with type 2 diabetes with normal blood glucose level and $\mathrm{HbA}_{1 \mathrm{c}}$. These results do not support the thesis that hyperglycemia is linked to increased carcinogenesis.

In an experimental model for the study of the influence of glucose concentration on tumor growth, Tannock and Kopelyan [9] found that higher glucose concentration increased the rate of cell division. However, at a glucose level of $5 \mathrm{mmol} / \mathrm{L}$ the intensity of cell division plateaus and any further increase in concentration does not lead to an increased rate of cell division. This suggests that hyperglycemia has no effect on cell proliferation.

Therefore, hyperinsulinemia rather than hyperglycemia seems to be the factor inducing intense cell proliferation. Activation of insulin receptors and insulin-like growth factor receptors (IGF-R) localized on the surface of cancer cells leads to cell proliferation [10]. Insulin resistance and hyperinsulinemia lead to increased concentration of insulin-like growth factors, activation of IGF-R receptors and activation of PI3K and Ras-Raf pathways, and result in increased cell division.

\section{Metformin - anticancer drug?}

Metformin has been successfully used for many years to treat patients with type 2 diabetes. A multicentre, randomized study conducted by UKPDS (United Kingdom Prospective Diabetes Study) [11] in patients with type 2 diabetes showed that treatment with metformin reduced the risk of myocardial infarction and diabetes-related death by $30 \%$ as compared with treatment with insulin and sulphonylurea derivatives. Numerous cohort studies have confirmed the thesis that patients with diabetes treated with metformin also have a lower risk of cancer incidence and mortality [12, 13].

Evans et al. [12] found a 23\% reduction in cancer incidence among patients treated with metformin as compared with sulphonylurea derivatives. Another Canadian study [14] during a five-year follow-up of 10309 people with diagnosed type 2 diabetes showed a significant cancer-related mortality reduction among patients receiving metformin in comparison to patients treated with oral sulphonylurea derivatives or insulin (3.5\% vs. $4.9 \%$ vs. $5.8 \%$ ). A Scottish cohort study [13] conducted among 12255 people suffering from type 2 diabetes showed a $7.3 \%$ rate of newly diagnosed cancer among patients treated with metformin as compared with
$11.6 \%$ of patients treated with other drugs. The median time between the diagnoses of diabetes and cancer was 3.5 and 2.6 years respectively ( $p=0.001$ ). Decensi et al. [15] found in turn in their meta-analysis a $31 \%$ reduction of cancer incidence and mortality in diabetic patients taking metformin.

Metformin belongs to the biguanide class derived from goat's rue (Galega officinalis), a herbaceous plant used in Ancient Egypt and medieval Europe [16-18]. It was first synthesized in 1922 by two scientists, Werner and Bellow from Trinity College, Dublin. The first biguanides (metformin and phenformin) were introduced in France in the 1950s after numerous publications by Jeane Sterne. They were withdrawn from the market after several years due to their severe adverse effects (phenformin) with particular focus on an increased risk of lactic acidosis. Having scored highly in many drug safety clinical trials, metformin (1,1-dimethylbiguanide) was introduced to the U.S. market in 1995 and gained more popularity with every year. The most common adverse effects after regular use of this drug are associated with the gastrointestinal tract, e.g. nausea, flatulence, vomiting, diarrhea. A small percentage of patients experience hives or other skin lesions. Lactic acidosis is very uncommon and affects mostly elderly people who suffer from circulation, liver or kidney failure. Apart from diabetics, metformin has also been successfully used in women with polycystic ovary syndrome, increasing the ovulation rate, and improving glucose tolerance and disordered lipid balance [19-21].

The hypoglycemic effect of metformin relies on the direct inhibition of gluconeogenesis and glycogenolysis in the liver. Metformin increases anaerobic glycolysis of peripheral tissue, particularly in skeletal muscles. Furthermore, it has an ability to enhance the number of GLUT4 glucose transporters and insulin receptors.

Metformin's mechanism of action is complex and may involve several pathways. The processes influenced by this drug include the following:

- activation of LKB1 (liver kinase B1)/AMPK (AMP-activated protein kinase) pathway,

- inhibition of cell division and/or promotion of apoptosis,

- promotion of autophagy,

- down-regulation of circulating insulin,

- activation of the immune system.

It is recognized that the basic mechanism of metformin action involves AMP-activated serine/threonine kinase, a type of protein that plays a key role in the regulation of cellular metabolism of both normal and cancer cells. AMPactivated protein kinase becomes activated under conditions of cellular energy deficit and a low AMP:ATP ratio. This resets the metabolic pathways from anabolic toward catabolic processes [22] and to promotion of e.g. glycolysis and oxidation of fatty acids; at the same time pathways of gluconeogenesis, protein, cholesterol and fatty acid synthesis are stopped [23]. AMP-activated protein kinase activation by metformin is mediated by LKB1 [24]. Liver kinase B1 is a suppressor protein. Its mutation is found in the hereditary PeutzJeghers syndrome characterized by the development of many hamartomatous polyps, skin lesions in the form of lentigines and a tendency to develop multiple carcinomas, particularly of the small intestine, stomach, pancreas and colon. 
The activation of AMPK by LKB1 leads to phosphorylation of tuberous sclerosis complex 2 (TSC-2), which in turn inhibits the mTOR protein (mammalian target of rapamycin), a key protein which regulates processes of cell growth and angiogenesis, and promotes cell division and protein synthesis. The inhibiting effect of AMPK on mTOR results in blocking of the PI3K/PKB/AKt pathway, thus downregulating the synthesis of many proteins, e.g. eukaryotic initiation factor 4e-binding protein-4E-SPs, ribosomal protein S6 kinase, responsible for mitotic promotion [25, 26] (Fig. 1). Metformin may also inhibit mTOR dependent pathways in the absence of AMPK, LKB1 and TSC2 in a Rag GTPase dependent manner [27]. AMP-activated protein kinase also promotes cellular autophagy through the phosphorylation of cyclin-dependent kinase inhibitor protein, p27 [28].

\section{The role of metformin in oncology}

As mentioned, metformin significantly lowers the death risk associated with malignant cancers. If we look closer at the figures from the numerous studies [15, 29, 30] we will see that this phenomenon applies only to some types of cancer, e.g. esophageal, liver, colorectal, pancreas, breast and lung. In a Taiwanese study, Lee et al. [29] found a substantial reduction in liver and colorectal cancer morbidity among patients taking metformin (HR: 0.58 and 0.38, respectively).

\section{Breast cancer}

Obesity and diabetes are acknowledged risk factors of breast cancer for peri- and postmenopausal women. According to Thor and Anderson [31] the risk increases by $20 \%$ and the cancers very often are estrogen receptor positive.

Many studies conducted on breast cancer lines have shown positive action of metformin on these malignant cells. Alimova et al. [33] studied in diverse subtypes of breast cancer cell lines the effect of metformin on receptor expression and molecular pathways that participate in cell proliferation and apoptosis. Metformin inhibited cell proliferation by blocking the cell cycle at the G1 checkpoint, and downregulated cyclin D1 and transcription factor E2F1 expression, with no impact on other cell cycle regulators, such as p27kip1 or p21WAF1. It has been proven that metformin inhibits the MAPK (mitogen activated protein kinase) signaling pathway as well as Act activity [34]. Another mode of metformin activity is suppressing the phosphorylation of signal transducer and activator of transcription Stat3, also responsible for cellular proliferation and apoptosis, angiogenesis and activation of expression of genes related to breast cancer survival [31]. The cytotoxic effect of metformin on breast cancer cells may also take place via damage to the poly(ADP-ribose) polymerases (PARPs) - enzymes responsible for genome integrity - and via activation of caspase associated with cell apoptosis [31, 35]. High and low-concentration metformin in in vitro studies inhibited erbB2 expression and showed biological activity against estrogen receptors (ER) [30]. According to Liu et al. [36] metformin in vitro and in vivo (nude mice strain) exerts an inhibiting effect

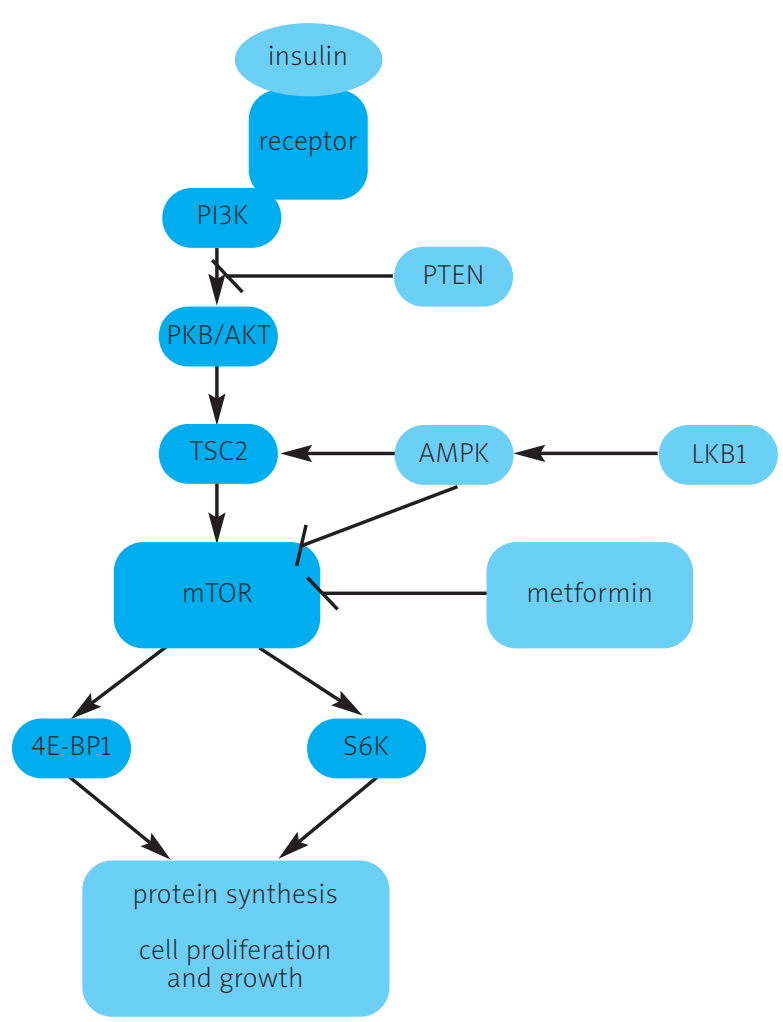

PTEN - phosphatase and tensin homologue deleted on chromosome 10; PI3K - phosphatidylinositol-3-kinase; PKB/AKT - protein kinase B/Akt; mTOR - mammalian target of rapamycin; TSC-2 - tuberous sclerosis complex 2; LKB1 - liver kinase B1; AMPK - AMP-activated protein kinase; 4E-BP1 eukaryotic initiation factor $4 E$-binding protein; $56 \mathrm{~K}$ - protein $S 6$ kinases

Fig. 1. The role of metformin in the etiology of cancer. Adapted from: Cancer Res 2007; 67: 10804-10812 [25] - reprinted with permission

in cell culture conditions and reduces tumor mass in animal models. Bernstein et al. [37] tested receptor status in carcinoma cells after previous surgery in 90 female patients with diabetes, treated with metformin and other antidiabetic medication. In their work they noted that the frequency of progesterone-positive receptors in women treated with metformin was significantly higher in comparison to the group treated with other medication and these results may be used in breast cancer therapy.

Scientists from Texas [32] analyzed responses to neoadjuvant chemotherapy for early-stage breast cancer in 2529 women over a 17-year period - 2374 women were nondiabetic, 68 diabetic using metformin and 87 diabetic using other treatment - and reported a complete pathological remission in $24 \%$ of women taking metformin versus $8 \%$ of women taking other antidiabetic medication and $16 \%$ of nondiabetic patients $(p=0.02)$. More randomized studies are necessary to ascertain whether metformin improves responses to chemotherapy in women suffering from breast cancer and whether there is a benefit of adding this drug to conventional treatment [38, 39]. 


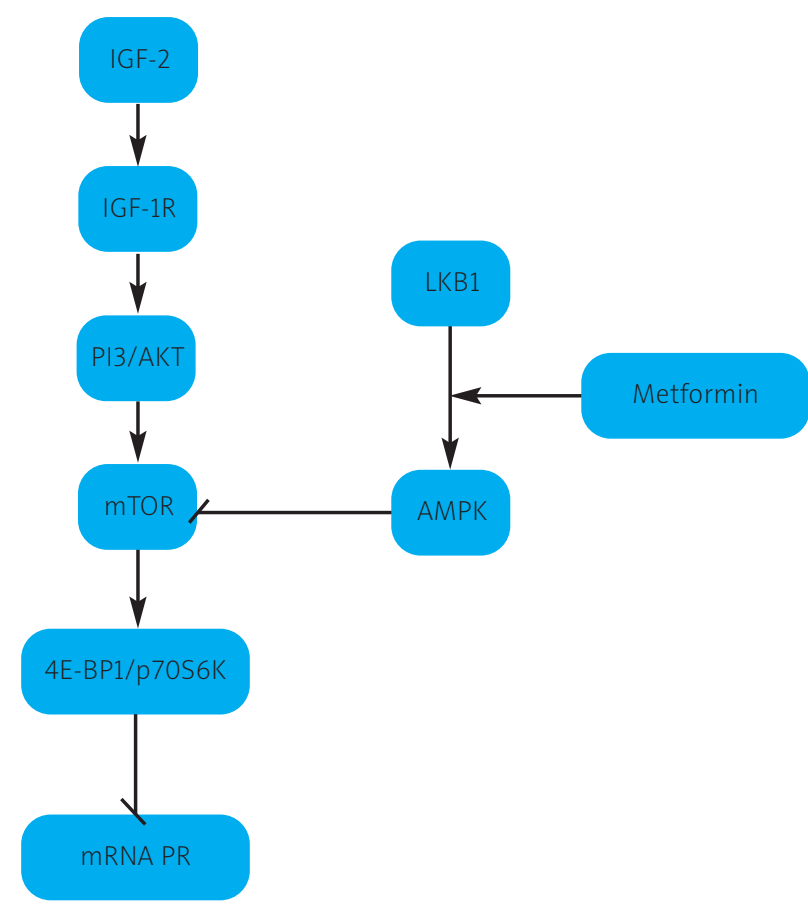

IGF-2 - insulin-like growth factor 2; IGR-1R - insulin-like growth factor receptor 1; PTEN - phosphatase and tensin homologue deleted on chromosome 10; PI3K/AKT - phosphatidylinositol-3-kinase/Akt; MTOR - mammalian target of rapamycin; AMPK - AMP-activated protein kinase; LKB1 - liver kinase B1; $4 E-B P 1$ - eukaryotic initiation factor $4 E$-binding protein; p70S6K - 70 protein $S 6$ kinases; $m R N A P R$ - progesterone receptor $m R N A$

Fig. 2. The effect of metformin on PR expression. Adapted from: J Steroid Biochem Mol Biol 2011; 126: 113-120 [50] - reprinted with permission

Ongoing phase II and III clinical trials evaluate its role in breast cancer, where mTOR is suggested to be the shield [40].

During the recent ASCO (American Society of Clinical Oncology) meeting (2011) it was reported that the Clinical Trials Group from the National Cancer Institute of Canada has initiated enrollment of over 3500 women with nodepositive and node-negative breast cancer who will receive metformin compared with placebo for 5 years [41].

\section{Colorectal cancer}

Colorectal cancer risk is higher in obese patients with type 2 diabetes. Patients treated with insulin are twice as likely to develop this type of cancer as compared to patients taking metformin [42]. It has been supported that aberrant crypt foci (crypts of Lieberkuhn) may play a role in colon cancer pathogenesis [43].

The inhibiting effect of metformin on intestinal epithelial cell proliferation and the development of aberrant crypt foci and polyps has been shown in an animal model. The mechanism of metformin-mediated suppression of the abovementioned precancerous states occurred via the most common way - through AMPK activation and mTOR inhibition [43].

Studies of colon cancer cell lines prove that AMPK activation is accompanied by lower expression of VEGF as well as GLUT1 and COX-2 glucose transporter, which may additionally result in cell apoptosis [46]. Other studies have shown that metformin also induces apoptosis in suppressor p53-deficient colon cancer cells [47].

The findings of these studies show that type 2 diabetic patients constitute a high risk group for colon cancer and suggest a preventive effect of metformin.

\section{Pancreatic cancer}

Jee et al. [6] estimated whether the increase in risk of death from pancreatic cancer depended on duration of diabetes. The scientists found that the mortality risk increased according to diabetes duration with a twofold rise in mortality for diabetes duration of less than 5 years and a threefold rise for diabetes duration of more than 10 years. The evidence provided by an American study [48] exploring the relationship between metformin and pancreatic cancer risk proved the protective effect of the drug. According to the authors it reduces the risk of pancreatic cancer by over a half (HR: 0.38, 95\% Cl: 0.22-0.69; $p=0.001$.

\section{Other cancers}

In breast and endometrial cancer alike, the presence of progesterone receptors (PR) plays a vital role. A study by Cui et al. [49] established a significant IGF1-induced reduction in the number of PR in breast cancer cells. This phenomenon has been linked with the activity of the $\mathrm{PI3K} / \mathrm{Akt} / \mathrm{mTOR}$ pathway and inhibition of PR gene transcription. Similar results were obtained by Xiu et al. [50] in an examination of endometrial cancer cell lines. The results of their study show that IGF2 mediates activation of the PI3K/AKt/mTOR pathway, 4E-BP and p70S6K phosphorylation and a significant increase in cell proliferation, while both IGF1 and IGF2 inhibit expression of the PR A/B gene (Fig. 2). The authors also demonstrated that metformin exerts a counteracting effect on the abovementioned processes and this may imply that introduction of this drug combined with progesterone supplementation would result in a better response to treatment.

\section{Ongoing clinical trials}

The promising results of many cohort and experimental studies triggered further clinical trials which aim to determine whether this inexpensive, generally available and safe medication can reduce cancer incidence or improve cancer prognosis. Another interesting issue demanding further studies is the aspect of metformin use in nondiabetic patients. Could this group also benefit from metformin treatment? Currently many phase I, II and III trials are under way to study metformin's effect on breast, prostate, endometrial and pancreatic cancer (Table 1). Perhaps in the near future metformin's antineoplastic activity will be generally recognized and eventually it will be applied in oncotherapy. 


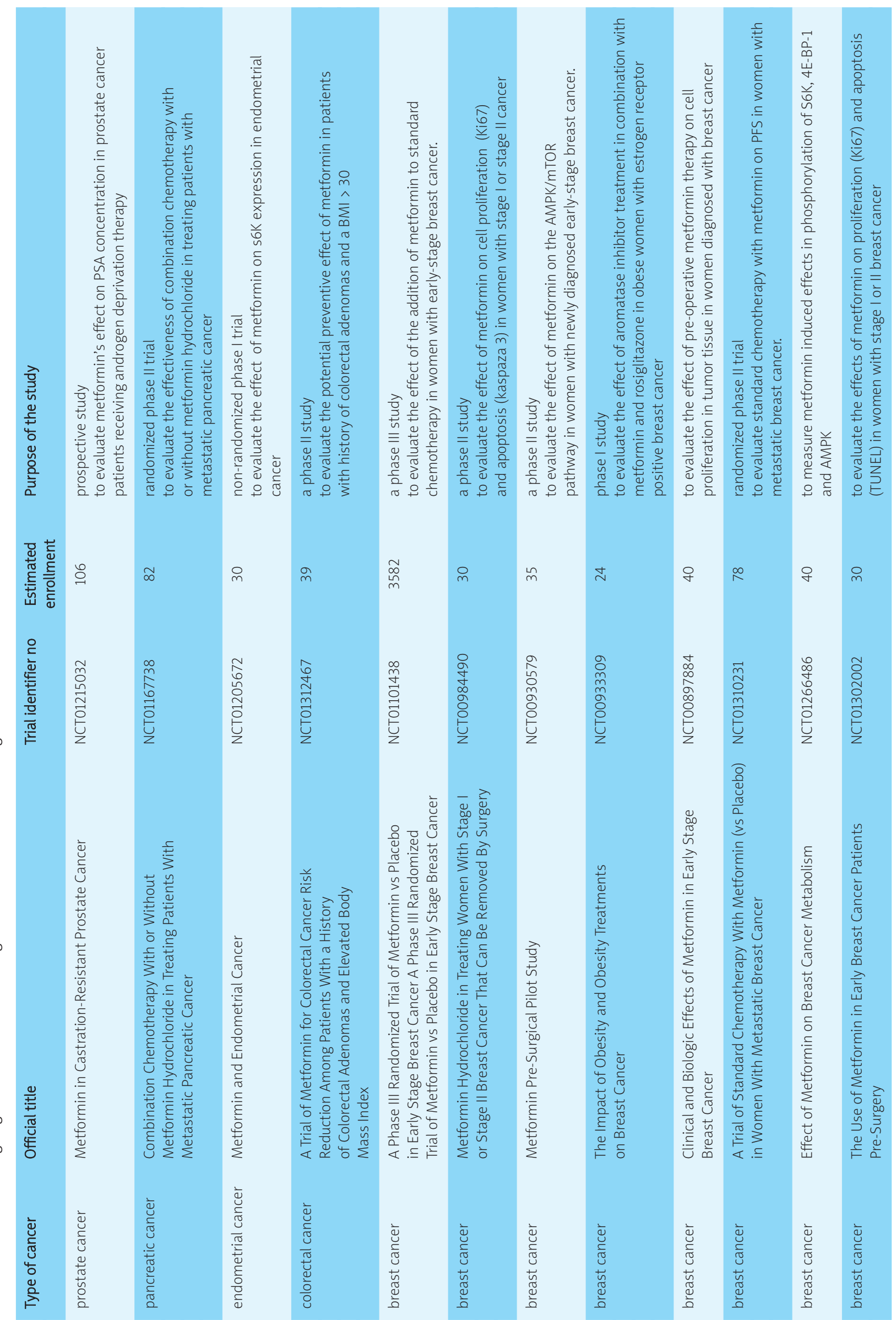




\section{References}

1. Kim YI. Diet, lifestyle, and colorectal cancer: is hyperinsulinemia the missing link? Nutr Rev 1998; 56: 275-279.

2. Del Giudice ME, Fantus IG, Ezzat S, McKeown-Eyssen G, Page D, Goodwin PJ. Insulin and related factors in premenopausal breast cance risk. Breast Cancer Res Treat 1998; 47: 111-120.

3. Yam D, Fink A, Mashiah A, Ben-Hur E. Hyperinsulinemia in colon, stom ach, and breast cancer patients. Cancer Lett 1996; 104: 129-132.

4. Park SM, Lim MK, Shin SA, Yun YH. Impact of prediagnosis smoking, alcohol, obesity, and insulin resistance on survival in male cancer patients: National Health Insurance Corporation Study. J Clin Oncol 2006; 24: 5017-5024.

5. Gerstein HC. Does insulin therapy promote, reduce, or have a neutral effect on cancers? JAMA 2010; 303: 446-447.

6. Jee SH, Ohrr H, Sull JW, Yun JE, Ji M, Samet JM. Fasting serum glucose level and cancer risk in Korean men and women. JAMA 2005; 293: 194-202.

7. Pollak M. Insulin and insulin-like growth factor signaling in neoplasia. Nat Rev Cancer 2008; 8: 915-928.

8. Johnson JA, Bowker SL. Intensive glycaemic control and cancer risk in type 2 diabetes: a meta-analysis of major trials. Diabetologia 2011; 54: 25-31.

9. Tannock IF, Kopelyan I. Influence of glucose concentration on growth and formation of necrosis in spheroids derived from a human bladder cancer cell line. Cancer Res 1986; 46: 3105-3110.

10. LeRoith D, Baserga R, Helman L, Roberts CT Jr. Insulin-like growth factors and cancer. Ann Intern Med 1995; 122: 54-59.

11. United Kingdom Prospective Diabetes Study (UKPDS). 13: Relative efficacy of randomly allocated diet, sulphonylurea, insulin, or metformin in patients with newly diagnosed non-insulin dependent diabetes followed for three years. BMJ 1995; 310: 83-88.

12. Evans JM, Donnelly LA, Emslie-Smith AM, Alessi DR, Morris AD. Metformin and reduced risk of cancer in diabetic patients. BMJ 2005 330: 1304-1305.

13. Libby G, Donnelly LA, Donnan PT, Alessi DR, Morris AD, Evans JM. New users of metformin are at low risk of incident cancer: a cohort study among people with type 2 diabetes. Diabetes Care 2009; 32: 1620-1625.

14. Bowker SL, Majumdar SR, Veugelers P, Johnson JA. Increased cancer-related mortality for patients with type 2 diabetes who use sulfonylureas or insulin. Diabetes Care 2006; 29: 254-258.

15. Decensi A, Puntoni M, Goodwin P, Cazzaniga M, Gennari A, Bonanni B, Gandini S. Metformin and cancer risk in diabetic patients: a systemic review and meta-analysis. Cancer Prev Res (Phila) 2010; 3: 1451 1461.

16. Witters LA. The blooming of the French lilac. J Clin Invest 2001; 108: 1105-1107.

17. Hadden DR. Goat's rue - French lilac - Italian fitch - Spanish sainfoin: gallega officinalis and metformin: the Edinburgh connection. J R Coll Physicians Edinb 2005; 35: 258-260.

18. Bailey CJ, Day C. Metformin: its botanical background. Pract Diab Int 2004; 21: 115-117.

19. Tessari P, Tiengo A. Metformin treatment of rats with diet induced overweight and hypertriglyceridemia decreases plasma triglyceride concentrations, while decreasing triglyceride and increasing ketone body output by the isolated perfused liver. Acta Diabetol 2008; 45: 143-145.

20. Ng EH, Wat NM, Ho PC. Effects of metformin on ovulation rate, hormonal and metabolic profiles in women with clomipheneresistant polycystic ovaries: a randomized, double-blinded placebo-controlled trial. Hum Reprod 2001; 16: 1625-1631.

21. Fleming R, Hopkinson ZE, Wallace AM, Greer IA, Sattar N. Ovarian function and metabolic factors in women with oligomenorrhoea treated with metformin in a randomized double blind placebo-controlled trial. J Clin Endocrinol Metab 2002; 87: 569-574.

22. Steinberg GR, Kemp BE. AMPK in health and disease. Physiol Rev 2009; 89: 1025-1078.

23. Hardie DG. AMP-activated/SNF1protein kinases: conserved guardians of cellular energy. Nat Rev Mol Cell Biol 2007; 8: 774-785.

24. Shaw RJ, Lamia KA, Vasquez D, Koo SH, Bardeesy N, Depinho RA, Montminy M, Cantley LC. The kinase LKB1 mediates glucose homeostasis in liver and therapeutic effects of metformin. Science 2005; 310: 1642-1646.
25. Dowling RJ, Zakikhani M, Fantus IG, Pollak M, Sonenberg N. Metformin inhibits mammalian target of rapamycin-dependent translation initiation in breast cancer cells. Cancer Res 2007; 67: 10804-10812.

26. Gotlieb WH, Saumet J, Beauchamp MC, Gu J, Lau S, Pollak MN Bruchim I. In vitro metformin anti-neoplastic activity in epithelial ovarian cancer. Gynecol Oncol 2008; 110: 246-250.

27. Kalender A, Selvaraj A, Kim SY, et al. Metformin, independent of AMPK, inhibits mTORC1 in rag GTPase-dependent manner. Cell Metab 2010; 11: 390-401.

28. Liang J, Shao SH, Xu ZX, et al. The energy sensing LKB1-AMPK pathway regulates $\mathrm{p} 27$ (kip1) phesphorylation mediating the decision to enter authophagy or apoptosis. Nat Cell Biol 2007; 9: 218-224.

29. Lee MS, Hsu CC, Wahlqvist ML, Tsai HN, Chang YH, Huang YC. Type 2 diabetes increases and metformin reduces total, colorectal, liver and pancreatic cancer incidences in Taiwanese: a retrospective population prospective cohort study of 800000 individuals. BMC Cancer 2011; 11: 20

30. Bosco JL, Antonsen S, Sørensen HT, Pedersen L, Lash TL. Metformin and incident breast cancer among diabetic women: a populationbased control-case study in Denmark. Cancer Epidemiol Biomarkers Prev 2011; 20: 101-111.

31. Thor A, Anderson SM. Clinical studies of metformin action in breast cancer. Am J Clin Oncol 2011. Educational book: 46-49.

32. Jiralerspong S, Palla SL, Giordano SH, et al. Metformin and pathologic complete responses to neoadjuvant chemotherapy in diabetic patients with breast cancer. J Clin Oncol 2009; 27: 3297-3302.

33. Alimova IN, Liu B, Fan Z, Edgerton SM, Dillon T, Lind SE, Thor AD. Metformin inhibits breast cancer cell growth, colony formation and induces cell cycle arrest in vitro. Cell Cycle 2009; 8: 909-915.

34. Schwartz GK, Shah MA. Targeting the cell cycle: a new approach to cancer therapy. J Clin Oncol 2008; 23: 9408-9421.

35. Zhuang Y, Miskimins WK. Metformin induces both caspase-dependent and poly(ADP-ribose) polymerase-dependent cell death in breast cancer cells. Mol Cancer Res 2011; 9: 603-615.

36. Liu B, Fan Z, Edgerton SM, Deng XS, Alimova IN, Lind SE, Thor AD. Metformin induces unique biological and molecular responses in triple negative breast cancer cells. Cell Cycle 2009; 8: 2031-2040.

37. Berstein LM, Boyarkina MP, Tsyrlina EV, Turkevich EA, Semiglazov VF. More favorable progesterone receptor phenotype of breast cancer in diabetics treated with metformin. Med Oncol 2011; 28: 12601263.

38. Garcia A, Tisman G. Metformin, B(12) and enhanced breast cancer response to chemotherapy. J Clin Oncol 2010; 28: e19.

39. Grenader T, Goldberg A, Shavit L. Metformin as an addition to conventional chemotherapy in breast cancer. J Clin Oncol 2009; 27: e259.

40. Guppy A, Jamal-Hanjani M, Pickering L. Anticancer effects of metformin and its potential use as a therapeutic agent for breast cancer. Future Oncol 2011; 7: 727-736.

41. Goodwin PJ, Stambolic V. Metformin, cancer risk and prognosis. Am J Clin Oncol 2011. Educational book: 42-45.

42. Renehan A, Smith U, Kirkman MS. Linking diabetes and cancer: a consensus on complexity. Lancet 2010; 375: 2201-2202.

43. Bird RP. Role of aberrant crypt foci in understanding the pathogenesis of colon cancer. Cancer Lett 1995; 93: 55-71.

44. Hosono K, Endo H, Takahashi H, et al. Metformin suppresses azoxymethane-induced colorectal aberrant crypt foci by activating AMP-activated protein kinase. Mol Carcinog 2010; 49: 662-671.

45. Tomimoto $A$, Endo $H$, Sugiyama $M$, et al. Metformin suppresses intestinal polyp growth in ApcMin/+ mice. Cancer Sci 2008; 99: 21362141.

46. Hwang JT, Ha J, Park IJ, Lee SK, Baik HW, Kim YM, Park OJ. Apoptotic effect of EGCG in HT-29 colon cancer via AMPK signal pathway. Cancer Lett 2007; 247: 115-121.

47. Buzzai M, Jones RG, Amaravadi RK, et al. Systemic treatment with the antidiabetic drug metformin selectively impairs p53-deficient tumor cell growth. Cancer Res 2007; 67: 6745-6752.

48. Li D, Yeung SC, Hassan MM, Konopleva M, Abbruzzese JL. Antidiabetic therapies affect risk of pancreatic cancer. Gastroenterology 2009; 137: 482-488.

49. Cui X, Zhang P, Deng W, Oesterreich S, Lu Y, Mills GB, Lee AV. Insulinlike growth factor-I inhibits progesterone receptor expression in breast cancer cells via the phosphatidylinositol 3-kinase/Akt/mammalian 
target of rapamycin pathway: progesterone receptor as a potential indicator of growth factor activity in breast cancer. Mol Endocrinol 2003; 17: 575-588.

50. Xie Y, Wang YL, Yu L, Hu Q, Ji L, Zhang Y, Liao QP. Metformin promotes progesterone receptor expression via inhibition of mammalian target of rapamycin (mTOR) in endometrial cancer cells. J Steroid Biochem Mol Biol 2011; 126: 113-120.

\section{Address for correspondence}

\section{Monika Pawałowska}

Department of Oncology

Poznan University of Medical Sciences

Szamarzewskiego 82/84

60-569 Poznań, Poland

tel. +48618549020

Submitted: $\quad$ 13.08.2011

Accepted: $\quad 2.04 .2012$ 